\title{
Measuring when Uber behaves as a substitute or supplement to transit: An examination of travel-time differences in Toronto
}

\author{
[Accepted in the Journal of Transport Geography]
}

\author{
Mischa Young \\ Department of Geography \& Planning \\ University of Toronto, Toronto, Canada, M5S 3G3 \\ mischa.young@mail.utoronto.ca
}

\author{
Jeff Allen \\ Department of Geography \& Planning \\ University of Toronto, Toronto, Canada, M5S 3G3 \\ Jeff.allen@mail.utoronto.ca
}

\author{
Steven Farber \\ Department of Human Geography \\ University of Toronto Scarborough, Toronto, Canada, M1C 1A4 \\ Steven.farber@utoronto.ca
}

\begin{abstract}
:
Policymakers in cities worldwide are trying to determine how ride-hailing services affect the ridership of traditional forms of public transportation. The level of convenience and comfort that these services provide is bound to take riders away from transit, but by operating in areas, or at times, when transit is less frequent, they may also be filling a gap left vacant by transit operations. These contradictory effects reveal why we should not merely categorize all ride-hailing services as a substitute or supplement to transit, and demonstrate the need to examine ride-hailing trips individually.

Using data from the 2016 Transportation Tomorrow Survey in Toronto, we investigate the differences in travel-times between observed ride-hailing trips and their fastest transit alternatives. Ordinary least squares and ordered logistic regressions are used to uncover the characteristics that influence travel-time differences. We find that ride-hailing trips contained within the City of Toronto, pursued during peak hours, or for shopping purposes, are more likely to have transit alternatives of similar duration. Also, we find differences in travel-time often to be caused by transfers and lengthy walk- and wait-times for transit. Our results further indicate that $31 \%$ of ride-hailing trips in our sample have transit alternatives of similar duration ( $\leq 15$ minute difference). These are particularly damaging for transit agencies as they compete directly with services that fall within reasonable expectations of transit service levels. We also find that $27 \%$ of ridehailing trips would take at least 30 minutes longer by transit, evidence for significant gapfilling opportunity of ride-hailing services. In light of these findings, we discuss recommendations for ride-hailing taxation structures.
\end{abstract}

Keywords: Ride-hailing; Uber; Public transit; Travel-time differences; Travel behaviour 


\section{Introduction}

Ride-hailing $(\mathrm{RH})$ companies, such as Uber and Lyft, claim to improve the mobility of their users and to "ignite opportunity by setting the world in motion" (Uber, 2019a). Many users appear to agree with this sentiment and appreciate the reliability and seamlessness of RH services as attested by their rapid growth and market valuations. Indeed, in less than a decade, RH companies are now among the most valuable within the transportation sector and have secured a large global user base. Uber - the most valuable RH company, with a market capitalization of over $\$ 72$ billion in 2018 - now counts over 75 million passengers in over 600 cities worldwide, and reports to have completed over 5 billion trips in its first near decade of existence (Iqbal, 2018).

Despite these striking figures, some scholars argue that RH services do not improve mobility to the degree claimed by RH companies (Schaller Consulting, 2018; Zwick and Spicer, 2018). Instead, they argue that RH services have simply replaced the mobility provided by other more sustainable modes, and have reduced the speed and appeal of surface transit modes by adding to congestion (Erhardt et al. 2019, Schaller, 2017; Castiglione et al., 2018). Moreover, scholars contend that the increase in RH may reduce the mobility of those that depend on transit, as transit agencies experiencing a revenue reduction may have to reduce transit supply.

Others, however, have refuted this concern by emphasizing the ability of $\mathrm{RH}$ to act as a supplement to transit; noting that $\mathrm{RH}$ can provide first/last mile services and deliver services that are not directly competing with existing transit lines (Rayle et al., 2016; Feigon and Murphy, 2016; Komanduri et al., 2018; Young, 2019). These benefits have gained considerable traction among transit agencies seeking to reduce operational 
costs as well as among policymakers charged with the difficult task of effectively regulating RH services. These differing perspectives accentuate the need to examine RH trips individually and to consider the factors that may influence each trip's level of competition with transit.

Accordingly, the objective of this paper is to determine the degree to which observed RH trips in Toronto, Canada compete or supplement public transit, and to uncover the user and trip characteristics that influence this relation. Policymakers in Toronto, and indeed in cities around the world, are in the midst of defining and updating regulatory frameworks governing RH services, and information pertaining to the degree of competition between RH and transit will undoubtedly prove useful.

\section{Literature review}

A growing concern with $\mathrm{RH}$ services is whether they affect the ridership of other, more sustainable modes of travel such as public transit. Indeed, this has become a major criticism of RH services and has led some to categorize them as detrimental to a city's sustainable transportation objectives (Henao, 2017). For instance, Clewlow and Mishra (2017) measured the transportation implications for major American cities following the arrival of Uber and concluded that, all else being equal, $\mathrm{RH}$ services were responsible for a $6 \%$ reduction in transit usage. Silver and Fisher-Baum (2015) voiced a similar concern when noting that "If Uber is worth its $\$ 50$ billion valuation, it will have to do more than win over the market historically occupied by the taxi and limo industry - it will have to identify new types of customers", referring to transit users (Silver and Fisher-Baum, 2015). This sentiment was further echoed by the New York Metropolitan Transportation Authority, which declared after observing a decline in transit ridership, that the popularity 
of Uber and other RH apps were direct contributors to this decline (Fitzsimons, 2017). Rayle et al. (2016) also came to a similar conclusion by showing that $33 \%$ of respondents in their San Francisco-based study would have selected transit as the next best alternative were it not for RH. They were, however, reluctant to associate RH to the observed decline in transit ridership, as they found that many car owners would elsewise have used their own car and that the availability of RH services could also facilitate a carless lifestyle by offering a suitable alternative in times of bad weather or when carrying heavy items. By comparing RH travel-times to their fastest transit alternatives, they further showed that $66 \%$ of their 283 surveyed RH trips would have been twice as long if conducted by public transit, and this led them to believe that RH may be filling a gap in areas where public transit and traditional taxi services are sparse. Differences in traveltime are further used to establish the gap-filling potential of RH in a study by Komanduri et al. (2018), which focuses on the not-for-profit RH company called RideAustin in Texas. They found that a majority of transit trips were slower by $40 \%$ or more when compared to equivalent RideAustin trips, and establish this without accounting for transit reliability (i.e. variability in service), which would likely have increased the discrepancies in travel duration even further (Wessel and Farber, 2019).

Despite travel-time being well established as a predictor for mode choice (Frank et al., 2008; Bhat and Sardesai, 2006), the travel-time savings provided by RH do not, by themselves, indicate that $\mathrm{RH}$ is filling a gap in poor transit service. By offering marginally faster alternatives to transit, $\mathrm{RH}$ services may be competing with reasonable transit service expectations and eroding transit agencies ridership base (Rayle et al. 2016). In order to correctly establish the gap-filling potential of $\mathrm{RH}$, a deeper 
understanding of transit supply is required in conjunction with demand side factors such as user information and data on the timing, purpose, and location of RH trips.

Undeterred by the purported congestion effects of RH in New York City, Bialik et al. (2015) using 6 months of Uber pick-up location data in 2014, substantiated the gapfilling potential of RH by showing that many of Uber's strongholds in New York City were in areas with low transit supply or where undergoing a similar trip via transit would have been very time consuming. Following this vein, Feigon and Murphy (2016) surveyed over 4,500 shared mobility users across seven large American cities, and found RH to account for the highest overall share of trips during late evening and at night often during periods when transit is less frequent. This finding was later corroborated by Young and Farber (2019a), in a study that considered the timing of RH trips in Toronto, Canada, and found RH to account for the highest proportion of trips during the night period $(11 \mathrm{pm}-5 \mathrm{am})$. To further support the argument that $\mathrm{RH}$ may serve as a complement to transit, Feigon and Murphy (2016) interviewed public sector representatives and reported how many of them perceived RH as an effective first/last mile solution. This finding was, however, refuted by Tirachini and del Rio (2019) in a study conducted in South America, as well as by Henao and Marshall (2018) in the US, which both found only 5\% of RH trips to be combined with other modes of transportation, including public transit.

Recognizing that RH may have heterogeneous effects on transit ridership, Hall et al. (2018) conducted a multi-city analysis and found Uber to act as a complement to transit in cities where transit ridership was low to begin with, and to behave as a substitute in cities where transit ridership was already high prior to Uber's arrival. This 
they explained, is due to the strong correlation between transit ridership and transit supply, and to Uber effectively rendering transit more appealing by ensuring decent mobility to transit users in areas or at times when transit is infrequent. Their data, however, were collected at a city scale using Google Trends search index, and aggregated to a monthly basis, which precluded them from establishing the characteristics of trips that were said to substitute or complement transit, and did not provide any information about the individual trip makers. Also recognizing that external factors may influence the way in which RH services impact public transit, Gehrke et al. (2019) found passengers belonging to low-income households to be more likely to replace public transit with RH. Their survey was however administered by RH drivers, which likely produced an unrepresentative sample, and it did not include information about the purpose of trips, other than for home-based travels inferred by self-reported home postal codes.

By reviewing existing research, it is clear that a more nuanced, trip level, approach is required to examine the nature of competition between $\mathrm{RH}$ and transit. $\mathrm{RH}$ is theorized to behave both as substitute and complement, and aggregate analyses will never be able to determine the relative sizes of each effect. Research must be designed to unpack the trip-level, user-level, and contextual factors that govern how we understand substitutionary and complimentary relationships between $\mathrm{RH}$ and transit trips. Accordingly, in this paper we analyze the user and trip-characteristics of a large sample of observed RH trips in Toronto, Canada, and compare these to the characteristics of the shortest-path transit alternative. We seek to explain the factors that make ride-hailing trips more or less competitive with public transit. 


\section{Methodology}

\subsection{Study area and data}

Toronto is the largest Canadian city and fourth largest in North America, with a population of 2.7 million (Statistics Canada, 2016). The greater metropolitan area of Toronto, commonly referred to as the Greater Golden Horseshoe (GGH) region has a population of 7.8 million (Statistics Canada, 2016). The Toronto region exhibits similar characteristics to those of other large North American cities; it has a high concentration of low-income households in its inner core, and the majority of high-income households are located in the car dependent suburbs and the exurbs in particular (Allen and Farber, 2019). Making Toronto somewhat unique within the North American context is the abundance of high-density residential towers built throughout its inner-suburbs during the 1960s and 1970s, which are home to many low-income residents (Hulchanski, 2010). Polycentric characteristics, such as the presence of transportation hubs and commercial districts outside the city core, reduce the disparity in socioeconomic attributes and travel behaviours between inner and outer neighbourhoods. Toronto's transit system is maintained and operated by the Toronto Transit Commission (TTC) and is the most heavily used transit system in Canada and has the third highest ridership in all of North America after only New York City and Mexico City. It is comprised of four subway lines, 11 streetcar routes, and more than 140 bus routes, which together provide extensive grid coverage of the City. The density of this grid-based system is further supported by free transfers between transit modes, which enable the buses and streetcars to serve as feeders for high-speed subway trips. The City of Toronto is also served by a regional commuter transit system (GO transit), which operates within the City's boundaries, but is predominantly used for longer distance commutes originating in peripheral suburban 
regions within the GGH. RH arrived in Toronto in 2012, but widespread adoption and use of these services began in the latter half of 2014 with the introduction of UberX.

The data used for this study were collected two years later by the 2016 Transportation Tomorrow Survey (TTS), a cross-sectional household travel survey conducted in the GGH (Data Management Group, 2017). The 2016 TTS uses a mixed sampling approach to maximize representativeness and address its continual decrease in response rates, especially from younger members of the population. In addition to traditional landline-based survey collection techniques, the 2016 TTS uses a web-based component to assist in the recruitment process, in order to capture a larger share of young adults (TTS, 2016). Previous research using this dataset has revealed the arrival of RH correlates to a significant decrease in taxi ridership and to an increase in active modes of travel (i.e. walking and cycling) for a younger market segment (20 to 39 year olds), but overall $\mathrm{RH}$ use was too small in scale to detect an influence on the ridership of transit (Young and Farber, 2019a).

\subsection{Travel-time estimation}

The TTS includes the origin, destination, and departure time of $1,851 \mathrm{RH}$ trips at a dissemination area level (refer to Figure 1) ${ }^{1}$. For each of these trips, we estimated car and transit-based travel-times and associated trip characteristics using the open-source routing software OpenTripPlanner. Walking network and GTFS data circa 2016 are used in order to align with the collection time of the TTS. These tools and data sources have been used to derive similar transit network variables in previous travel behaviour studies for the Toronto region (Allen \& Farber, 2018; Howell et al., 2018). Transit travel-time estimates

\footnotetext{
${ }^{1}$ RH trips displayed in Figure 1 are calculated using their estimated shortest paths between centroids of dissemination areas.
} 
include walking time to/from stops, time waiting for a vehicle, and any time required to transfer between vehicles if necessary. Transit itineraries were estimated and averaged every minute for 15 minutes before and after the stated departure time in the survey. This accounts for the likelihood that respondents did not depart exactly when stated within the survey, as well as due to the reliability of GTFS-based travel-time estimates (Farber et al., 2016; Wessel and Farber, 2019).

RH trip times are calculated by taking the in-vehicle travel-time (computed by using the origin, destination, departure time, and ensuing level of congestion for that departure time), and adding 5.78 minutes to account for wait-time. Actual wait-times were not included in the 2016 TTS survey, and were therefore based on the average computed on Uber data in the City of Toronto for this approximate time period (Wenting et al., Forthcoming). The use of an average wait-time is appropriate in this context, as the wait-time in downtown Toronto was within 1 minute, on average, of that of several of the City's suburbs. Moreover, this average wait-time is comparable to previous work by Rayle et al. (2016), which found the average wait-time for RH trips in San Francisco to be 5.1 minutes. We also estimate the cost of RH trips by adding the per minute $(\$ 0.18)$ and per kilometer cost $(\$ 0.81)$ to the booking fee $(\$ 2.75)$ and base fare $(\$ 2.50)$ of $\mathrm{RH}$ trips $^{2}$ (Uber, 2019b). Descriptive statistics for RH trips in our sample as well as characteristics of their fastest transit alternative are summarized in Section 4.

\footnotetext{
2 RH costs were estimated using UberX prices, as these represent the lion share of RH trips in our sample. Lyft only arrived in Toronto in December 2016, a few months after the data collection period. Unfortunately we do not have information pertaining to the occurrence and extent of surge pricing, but acknowledge that this may influence the cost of RH trips and that we are probably underestimating this price. All values are in Canadian Dollars.
} 


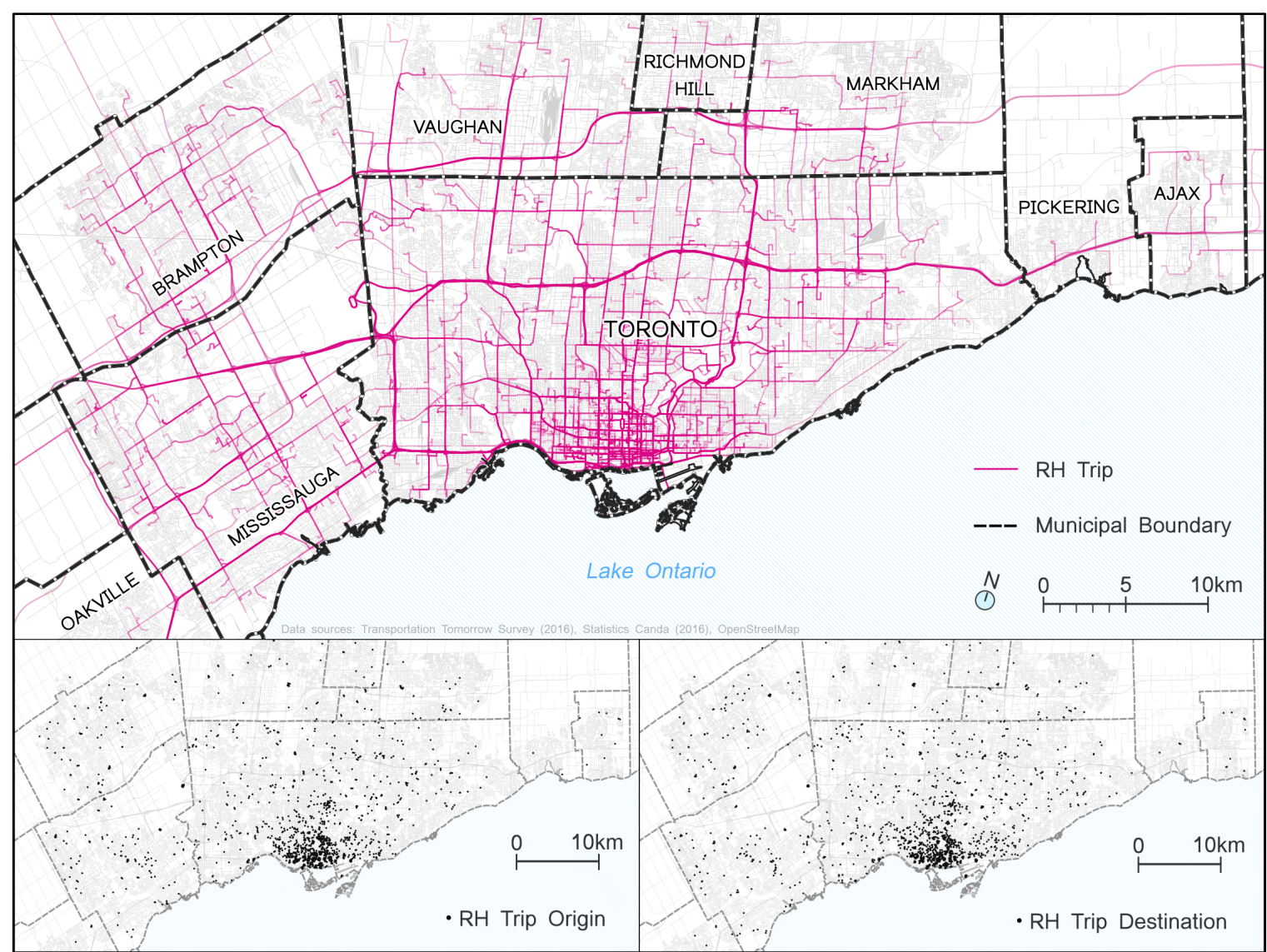

Figure 1. Ride-hailing trips in the Toronto area

Note: The opacity of lines on the map represents a higher density of RH trips on these road segments.

\subsection{Statistical analysis}

Because of item specific non-responses and to some RH trips not having a feasible transit alternative (i.e. trip either starting or ending beyond the survey boundaries or walking distances $>5 \mathrm{~km}$ ), the analysis is carried out on a sample of $1,578 \mathrm{RH}$ trips.

The main objective of this paper lies in understanding the factors that influence the difference in travel-time between RH and transit, and in determining the proportion and composition of RH trips that may be categorized as a substitute or supplement to transit. To achieve this, we first conduct an OLS regression with log transformations to determine whether and how each user's personal characteristics and trip attributes influence the ratio between Transit and RH travel-time. We present the coefficients of the 
full and reduced model, obtained through a backward stepwise selection process. After examining the distribution of travel-time differences as a ratio, we turn to absolute differences and separate $\mathrm{RH}$ trips into three categories to ease interpretation and to facilitate future policy recommendations. We pursue this part of the analysis on absolute differences to incorporate sensible transit service expectations, and conduct an ordered logistic regression to further substantiate the policy-relevance of the results established in the OLS model.

\section{Results}

\subsection{Descriptive statistics}

We present the socioeconomic characteristics of RH users as well as information on the start-time, purpose, and location of RH trips in Table 1. The characteristics of our entire sample population (all modes combined) are also included for comparison. Chi-square $\left(\chi^{2}\right)$ tests indicate the presence of a statistically significant relationship between these variables and RH usage (with the exception of gender). The main takeaways from Table 1 are that RH users are wealthier, younger, and more likely to own a transit pass than the average population. They are also less likely to own a car or have a drivers' licence. We also determine that RH trips are twice as likely than other modes to be Home-based other, and find that they are more likely to occur in the evening or at night as well as within the City of Toronto boundaries.

Table 1. RH user and trip characteristics

\begin{tabular}{llrrrrrr}
\hline & \multicolumn{2}{c}{ RH trips } & \multicolumn{2}{r}{ Transit trips } & \multicolumn{2}{r}{ All trips } \\
\hline Number of observations & \multicolumn{2}{c}{$\mathrm{n}=1,578$} & $\mathrm{n}=91,437$ & $\mathrm{n}=798,000$ \\
\hline Variables & Freq. & Pct. & Freq. & Pct. & Freq. & Pct. \\
\hline \multirow{3}{*}{ Income } & $\$ 0-39,999$ & 189 & 12.0 & 15,561 & 17.0 & 96,000 & 12.0 \\
\cline { 2 - 8 } & $\$ 40,000-59,999$ & 333 & 21.1 & 11,496 & 12.6 & 100,000 & 12.6 \\
\cline { 2 - 9 } & $\$ 60,000-99,999$ & 149 & 9.4 & 19,601 & 21.4 & 174,000 & 21.9 \\
\hline
\end{tabular}




\begin{tabular}{|c|c|c|c|c|c|c|c|}
\hline & $\$ 100,000+$ & 768 & 48.7 & 30,669 & 33.5 & 289,000 & 36.3 \\
\hline & Decline/don't know & 139 & 8.8 & 14,110 & 15.4 & 138,000 & 17.3 \\
\hline \multirow{3}{*}{ Age } & $18-29$ & 525 & 33.3 & 30,762 & 33.6 & 156,000 & 19.6 \\
\hline & $30-59$ & 959 & 60.8 & 46,177 & 50,5 & 416,000 & 52.2 \\
\hline & $60+$ & 94 & 6.0 & 14.498 & 15.9 & 226,000 & 28.3 \\
\hline \multirow{2}{*}{ Gender } & Female & 835 & 52.9 & 50,813 & 55.6 & 410,000 & 51.4 \\
\hline & Male & 743 & 47.1 & 40,624 & 44.4 & 388,000 & 48.6 \\
\hline \multirow{2}{*}{$\begin{array}{l}\text { Driver's } \\
\text { licence }\end{array}$} & Yes & 1231 & 78.0 & 59,546 & 65.1 & 683,000 & 85.5 \\
\hline & No & 347 & 22.0 & $29,229^{\mathrm{a}}$ & 32.0 & $110,000^{\mathrm{a}}$ & 14.5 \\
\hline \multirow{2}{*}{$\begin{array}{c}\text { Transit } \\
\text { pass }\end{array}$} & Yes & 257 & 16.3 & 36,190 & 40.0 & 56,000 & 7.0 \\
\hline & No & 1321 & 83.7 & $54,755^{\mathrm{a}}$ & 60.0 & $737,000^{\mathrm{a}}$ & 93.0 \\
\hline \multirow{4}{*}{$\begin{array}{l}\text { Number } \\
\text { of } \\
\text { vehicles }\end{array}$} & 0 & 534 & 33.8 & 25,818 & 28.2 & 47,000 & 5.9 \\
\hline & 1 & 632 & 40.1 & 36,511 & 39.9 & 266,000 & 33.3 \\
\hline & 2 & 305 & 19.3 & 22,758 & 24.9 & 350,000 & 43.8 \\
\hline & $3+$ & 107 & 6.8 & 6350 & 6.9 & 136,000 & 18.1 \\
\hline \multirow{5}{*}{$\begin{array}{l}\text { Start- } \\
\text { time }\end{array}$} & Morning (5 - 10am) & 265 & 16.8 & 32,361 & 35.4 & 228,000 & 28.5 \\
\hline & Midday (10am - 3pm) & 201 & 12.7 & 16,099 & 17.6 & 197,000 & 24.7 \\
\hline & Afternoon $(3-7 \mathrm{pm})$ & 439 & 27.8 & 33,840 & 37.0 & 267,945 & 33.6 \\
\hline & Evening $(7-11 \mathrm{pm})$ & 427 & 27.1 & 7,735 & 8.5 & 91,000 & 11.4 \\
\hline & Night (11pm - 5am) & 246 & 15.6 & 1,402 & 1.5 & 15,000 & 1.9 \\
\hline \multirow{5}{*}{$\begin{array}{c}\text { Trip } \\
\text { purpose }\end{array}$} & Home based Work (HBW) & 522 & 33.2 & 46,934 & 51.3 & 261,000 & 32.8 \\
\hline & Home based School (HBSc) & 106 & 6.7 & 18,178 & 18.8 & 70,000 & 8.8 \\
\hline & Home based Shopping (HBSh) & 90 & 5.7 & 5,922 & 6.5 & 103,000 & 12.9 \\
\hline & Home based Other (HBO) & 644 & 40.8 & 13,406 & 14.7 & 162,000 & 20.3 \\
\hline & Other combinations (Non-Home) & 216 & 13.7 & 7,997 & 8.7 & 201,000 & 25.2 \\
\hline \multirow{3}{*}{$\begin{array}{l}\text { Trip } \\
\text { location }\end{array}$} & City of Toronto & 1162 & 73.6 & 56,684 & 62.0 & 211,000 & 26.5 \\
\hline & City to/from suburb & 172 & 10.9 & 20,681 & 22.6 & 99,000 & 12.4 \\
\hline & Entirely suburban & 244 & 15.5 & 14,072 & 15.4 & 488,000 & 61.1 \\
\hline
\end{tabular}

${ }^{a}$ Approximately $0.5-2 \%$ of responses were removed from the Driver's license and Transit Pass categories because of "Unknown" responses.

We present RH and transit alternative trip characteristics in Table 2. Assuming single-occupancy, RH trips are found to be much faster and more expensive than transit, but the sheer number of equivalent transit trips that can be achieved in one transfer or less $(84.5 \%)$ attests to the high quality of the transit network in Toronto. That being said, not all RH trips can easily be achieved by transit, as many include long wait-times and walk- 
times that make them unattractive or require numerous transfers. We also find buses to comprise nearly half of the fastest transit alternatives in our observed RH trip sample.

Table 2. Descriptive statistics of RH trips and their fastest transit alternative

\begin{tabular}{|c|c|c|c|}
\hline \multirow[b]{2}{*}{ Trip Characteristics } & & \multicolumn{2}{|c|}{ GGH $(n=1,578)$} \\
\hline & & Median & Mean \\
\hline RH trip total duration (min.) & & 17.1 & 20.6 \\
\hline RH in-vehicle time (min.) & & 11.3 & 14.8 \\
\hline Transit alternative total duration (min.) & & 38.8 & 47.2 \\
\hline Transit in-vehicle time (min.) & & 19.1 & 23.8 \\
\hline Transit wait-time (min.) & & 5.8 & 8.7 \\
\hline Transit walk-time (min.) & & 13.4 & 14.8 \\
\hline RH cost $(\$)$ & & 12.2 & 15.7 \\
\hline \multirow[t]{2}{*}{ Transit cost $(\$)$} & & 3.3 & 3.9 \\
\hline & & Freq. & Pct. \\
\hline \multirow{5}{*}{ Number of transfers } & 0 & 716 & 45.4 \\
\hline & 1 & 618 & 39.2 \\
\hline & 2 & 213 & 13.5 \\
\hline & 3 & 23 & 1.5 \\
\hline & 4 & 8 & 0.5 \\
\hline \multirow{3}{*}{ Alternative transit mode used ${ }^{\mathrm{a}}$} & Bus & 993 & 62.9 \\
\hline & Streetcar & 571 & 36.2 \\
\hline & Subway & 497 & 31.5 \\
\hline
\end{tabular}

a The total percentage for Alternative transit mode used category does no sum to $100 \%$ because $26.1 \%$ trips include more than one mode.

\subsection{The difference in travel-time}

The difference in travel-time is first presented as a ratio in Figure 2. Since transit traveltimes are longer than $\mathrm{RH}$, we set:

$$
\delta=\text { Transit }_{t} / R H_{t}
$$

Where $\delta$ measures the ratio between $\mathrm{RH}$ and transit trip durations. Similarly to Rayle et al. (2016), who also compute a travel-times ratio between RH and transit, we consider trips with $\delta$ near 1.0 to represent those with comparable transit alternatives and where RH thus behaves competitively. Trips with high $\delta$ are those for which transit was 
incrementally slower than $\mathrm{RH}$, and therefore less of a competitive trip. The average $\mathrm{RH}$ trip in our sample is 2.3 times faster than its transit alternative (See Figure 2).

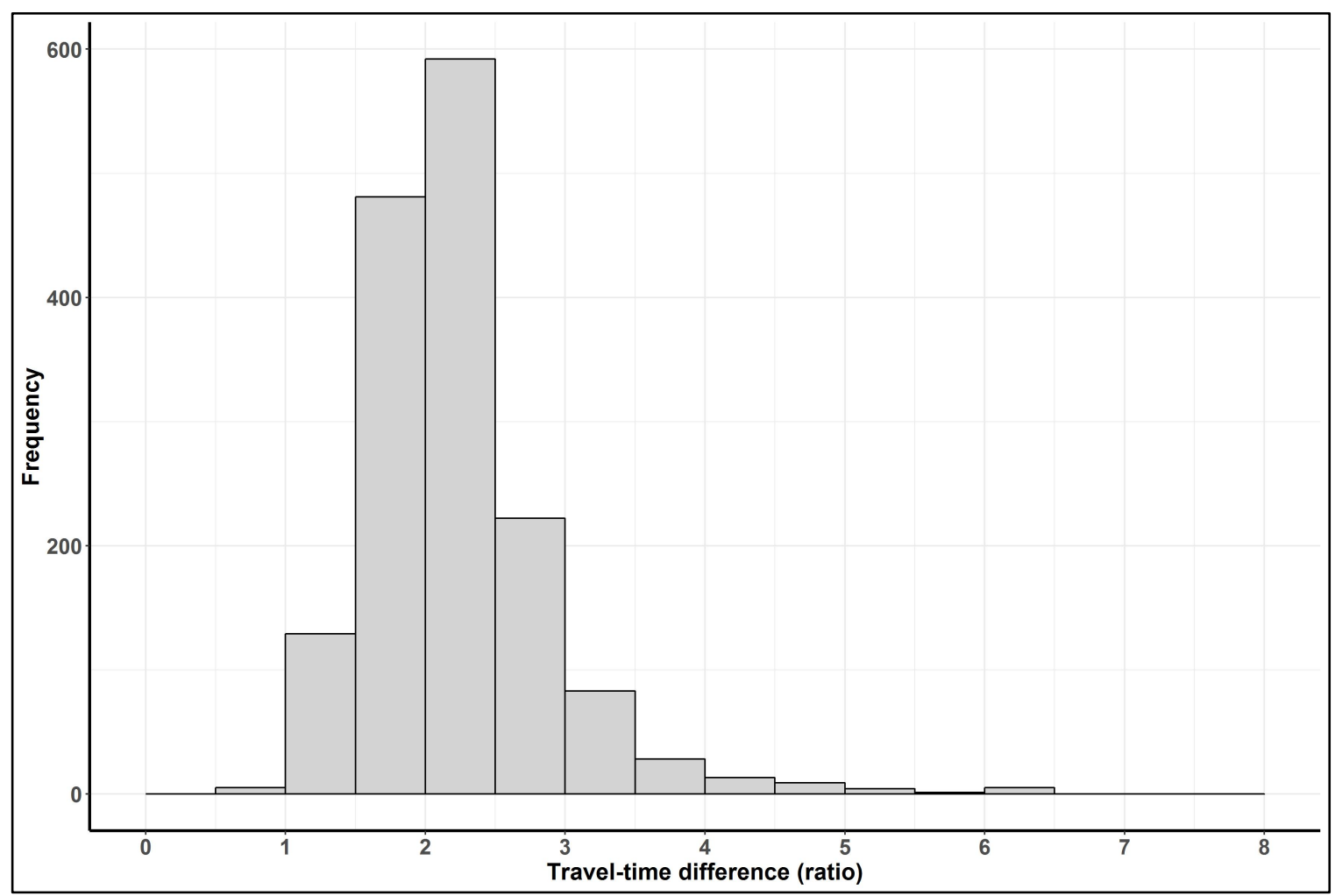

Figure 2. The ratio between transit and RH travel-time

To understand whether users and trip characteristics influence the position of $\mathrm{RH}$ trips within this distribution, we conduct an OLS regression (see Table 3), and use variance inflation factors to ensure that multicolinearity is not an issue. Both the full and reduced models display a relatively high explanatory power $\left(\mathrm{R}^{2}=0.58\right)$, but we choose to focus our interpretation on the reduced model as an ANOVA test reveals the full model to not be a significant improvement. Positive regression coefficients indicate higher $\delta$, and therefore less competition between transit and RH. Negative coefficients indicate lower $\delta$, and therefore more potential for competition. 
Table 3. Ordinary least square regression to determine the factors that influence the ratio between transit and RH travel-times.

\begin{tabular}{|c|c|c|c|}
\hline \multirow{2}{*}{ Variables } & & \multicolumn{2}{|c|}{ Dependent variable: $\log (\delta)$} \\
\hline & & Full model & Reduced model \\
\hline \multirow[t]{5}{*}{ Income } & $\$ 0-39,999$ & $0.026^{*}$ & - \\
\hline & $\$ 40,000-59,999$ & 0.004 & - \\
\hline & $\$ 60,000-99,999$ & -0.007 & - \\
\hline & $\$ 100,000+$ & Reference & - \\
\hline & Decline/don't know & 0.014 & - \\
\hline \multirow[t]{3}{*}{ Age } & $18-29$ & Reference & Reference \\
\hline & $30-59$ & $0.019 * *$ & 0.015 \\
\hline & $60+$ & $-0.043 * *$ & $-0.45 * *$ \\
\hline \multirow[t]{2}{*}{ Gender } & Female & Reference & - \\
\hline & Male & 0.011 & - \\
\hline \multirow[t]{2}{*}{ Driver's licence } & Yes & Reference & Reference \\
\hline & No & $0.019 *$ & $0.019 *$ \\
\hline \multirow[t]{2}{*}{ Transit pass } & Yes & Reference & - \\
\hline & No & 0.009 & - \\
\hline \multirow[t]{4}{*}{ Number of vehicles } & 0 & Reference & - \\
\hline & 1 & -0.014 & - \\
\hline & 2 & 0.004 & - \\
\hline & $3+$ & -0.024 & - \\
\hline \multirow[t]{5}{*}{ Start-time } & Morning (5 - 10am) & Reference & Reference \\
\hline & Midday (10am - 3pm) & $0.144 * * *$ & $0.145 * * *$ \\
\hline & Afternoon (3-7pm) & -0.003 & -0.004 \\
\hline & Evening $(7-11 \mathrm{pm})$ & $0.094 * * *$ & $0.092 * * *$ \\
\hline & Night (11pm - 5am) & $0.067 * * *$ & $0.066 * * *$ \\
\hline \multirow[t]{5}{*}{ Purpose } & HBW & Reference & Reference \\
\hline & HBSc & $0.043 * *$ & $0.041 * *$ \\
\hline & HBSh & $-0.039 *$ & $-0.034^{*}$ \\
\hline & $\mathrm{HBO}$ & 0.005 & 0.007 \\
\hline & Non-Home & -0.016 & -0.016 \\
\hline \multirow[t]{3}{*}{ Geography $^{3}$} & City of Toronto trip & Reference & Reference \\
\hline & City to/from suburb trip & -0.005 & 0.001 \\
\hline & Suburban trip & $0.052 * * *$ & $0.052 * * *$ \\
\hline \multicolumn{2}{|l|}{$\log ($ transit wait-time $)$} & $0.190 * * *$ & $0.191 * * *$ \\
\hline $\log ($ walk-time $)$ & & $0.244 * * *$ & $0.242 * * *$ \\
\hline \multirow[t]{3}{*}{ Number of transfers } & 0 & Reference & Reference \\
\hline & 1 & $0.036 * * *$ & $0.035 * * *$ \\
\hline & $2+$ & $0.067 * * *$ & $0.067 * * *$ \\
\hline \multicolumn{2}{|l|}{$\log ($ transit cost $)$} & $-0.091 * *$ & $-0.094 * * *$ \\
\hline \multicolumn{2}{|l|}{ Subway } & $-0.082 * * *$ & $-0.084 * * *$ \\
\hline \multicolumn{2}{|l|}{ Streetcar } & $0.101 * * *$ & $0.098 * * *$ \\
\hline \multicolumn{2}{|l|}{ Bus } & $0.051 * * *$ & $0.051 * * *$ \\
\hline \multicolumn{2}{|l|}{ Constant } & $-0.261 * * *$ & $-0.241 * * *$ \\
\hline \multicolumn{2}{|c|}{ Number of observations: } & $1,489^{\mathrm{a}}$ & $1,489^{\mathrm{a}}$ \\
\hline \multicolumn{2}{|c|}{ R-square } & 0.583 & 0.580 \\
\hline \multicolumn{2}{|l|}{ Adjusted R-square } & 0.575 & 0.574 \\
\hline
\end{tabular}

Note: $* \mathrm{p}<0.1 ; * * \mathrm{p}<0.05 ; * * * \mathrm{p}<0.01$

${ }^{\text {a }}$ Sample of 1,489 rather than 1,578 observations because of the removal of outliers.

3 The term suburb in this context is used to refer to any area outside of the City of Toronto limits. 
Overall, person-level characteristics do not tend to be significant predictors of $\delta$. Once an individual has chosen to use $\mathrm{RH}$, their personal characteristics do not seem to be an important factor in how much travel-time is saved by using RH rather than transit. In particular, we find income, gender, monthly transit pass ownership, and the number of vehicles per household all to be insignificant in the reduced model. Interestingly, older adults, aged 60 and above, tend to have significantly lower $\delta$ than those aged between 1829 years old, meaning that older people are more likely to partake in competitive $\mathrm{RH}$ trips. This could be due to some older adults not wanting, or being able, to walk the necessary distance to reach transit stops, and to them choosing to use $\mathrm{RH}$ even while similar transit services are available.

Trip characteristics are found to have a much greater impact on $\delta$. RH trips that start during off-peak hours are less likely to be competitive as transit frequency is lower during these periods. Home-based shopping trips are shown to have lower $\delta$ than the reference Home-based work purpose category, implying that shoppers may prefer to use RH when returning home with bags and purchases, regardless of whether transit alternatives of similar duration are present. Suburban $\mathrm{RH}$ trips are found to be less competitive than those contained within the City of Toronto limits. This could be due to lower levels of transit services outside of the City, as well as a lack of service and fare integration for trips that cross municipal boundaries.

With regards to the trip characteristics of the fastest transit alternative, we find that a $1 \%$ increase in transit wait-time results in an increase in $\delta$ by $0.19 \%$. Similarly, a $1 \%$ increase in walk-time results in a $0.24 \%$ increase in $\delta$, implying that less convenient transit options are less competitive. Trips with direct transit alternatives are also shown to 
have smaller $\delta$, especially in comparison to those that require two transfers or more. An increase in transit costs is also shown to negatively impact $\delta$, but not as much as other transit attributes. This is probably because the majority of RH trips occur entirely within the City of Toronto limits, and equivalent transit trips therefore only cost a flat fee of $\$ 3.25$ (or $\$ 3.00$ when using a Presto card). GO transit is the only service to use distancebased fare pricing and is employed in $6.8 \%$ of alternative transit trips. $\mathrm{RH}$ costs were not included in the model due to their collinearity with RH duration. Finally, we include dummy variables to reflect the transit modes of the transit alternative, and find subways to be indicative of trips with more similar travel times to RH. Conversely, trips that necessitate the use of buses or streetcars are more likely to be longer in duration, and therefore more supplementary.

\subsection{Categorization of RH trips based on their travel-time difference with transit}

Policymakers may be interested in influencing demand for RH trips depending on how directly they compete with transit. To estimate this, we categorize RH trips based on absolute difference in travel-time rather than a ratio and set:

$$
\Delta=\text { Transit }_{t}-R H_{t}
$$

In contrast to Rayle et al. (2016), we conduct this part of the analysis on absolute differences to incorporate sensible transit service expectations, and to not automatically categorize transit services as unsatisfactory simply for taking twice as long as RH trips. This is to avoid categorizing a 10-minute transit trips as non-competitive, just because it takes 5 minutes by $\mathrm{RH}$, and issue of small denominators common to statistical analysis of ratios. 
In the above equation, $\Delta$ is a measure of how much time the traveller saved by using RH rather than transit. Accordingly, we consider trips with low $\Delta$ to represent those where transit was a viable and competitive alternative to RH. Similarly, trips with high $\Delta$ are those for which transit was much slower than $\mathrm{RH}$, and therefore less of a competitive trip. Despite $\Delta$ being positively skewed, this distribution illustrates the quality of Toronto's transit network; half of all RH trips in our sample could be achieved by transit with less than a 21-minute penalty (See Figure 3). We conduct an OLS regression to understand whether user and trip characteristics influence the position of RH trips within this travel-time difference distribution, and similarly find trip characteristics to have a much larger impact than user attributes. To avoid redundancy with the ratio OLS model already presented, we only include this model's results in Appendix A. 


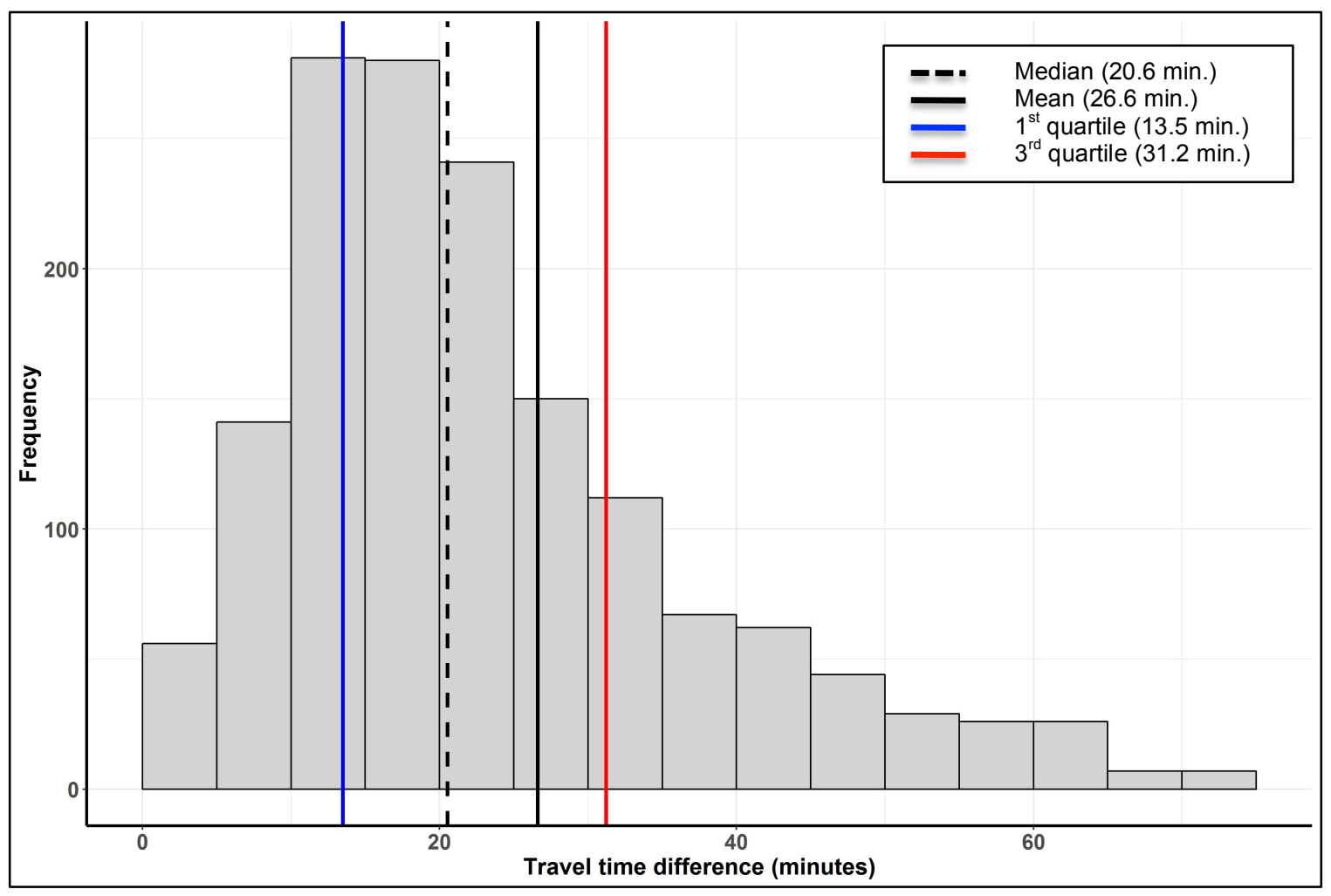

Figure 3. The absolute difference in travel-time between $\mathrm{RH}$ trips and their fastest transit alternatives

The selection of a $\Delta$ threshold for categorizing $\mathrm{RH}$ trips as substitutionary or supplementary to transit is obviously subjective. We begin by using the $1^{\text {st }}$ and $3^{\text {rd }}$ quartile of the travel-time difference distribution as the upper and lower cut-off points of our categorization. This provides $\Delta$ thresholds of 13.5 and 31.2 minutes, with trips with $\Delta<13.5$ classified as competitive, and those with $\Delta>31.2$ classified as supplementary.

From a policy perspective, these thresholds pose a serious problem, as they require governments to have information on the duration of all $\mathrm{RH}$ trips in their city and to know the duration of their fastest transit alternatives. Moreover, if the intention is to use these categories to inform policy work and discourage overly competitive RH trips, then perhaps using intuitive round numbers may be more appropriate to communicate and gain the public's approval. With this in mind, we considered a number of similar, but 
more intuitive, threshold pairs in proximity to the $1^{\text {st }}$ and $3^{\text {rd }}$ quartile, and eventually decided to use the $\Delta=15$ and $\Delta=30$ marks as cut-off points, as these most closely resembled the distribution produced by the quartiles. This gives rise to the following categorization.

$$
R H \text { trip categories }=\left\{\begin{array}{l}
\text { Type A, if } \Delta \leq 15 \mathrm{~min} . \\
\text { Type B, if } 15<\Delta<30 \mathrm{~min} . \\
\text { Type } \mathrm{C}, \text { if } \Delta \geq 30 \mathrm{~min} .
\end{array}\right.
$$

In Figure 4 we display Type A and C RH trips on a map of Toronto using their estimated shortest paths. The opacity of lines on the map represents a higher density of RH trips on these road segments. We notice that Type A trips, those with minimal time savings, are typically located in, or near, the central core of the city, and especially coincident with major transit arteries such as the subway and extensive streetcar network. Type C trips on the other hand are often entirely located in the outer regions of the City, in areas with lower transit frequency, and seemingly making more extensive use of the highway system. The geographic divide between competitive and complimentary trips is quite clear, with trips occurring in the downtown core predominantly being far more competitive with transit than those in the suburbs. Despite this, the map also depicts Type $\mathrm{C}$ density along the highways entering the downtown core, a destination that is served superbly by public transit. This hints at the potential to replace Type $\mathrm{C}$ trips with firstmile RH solutions, which will be discussed further as a policy recommendation. An additional set of maps illustrating the origin and destination of Type A and Type C trips is presented in Appendix B. 


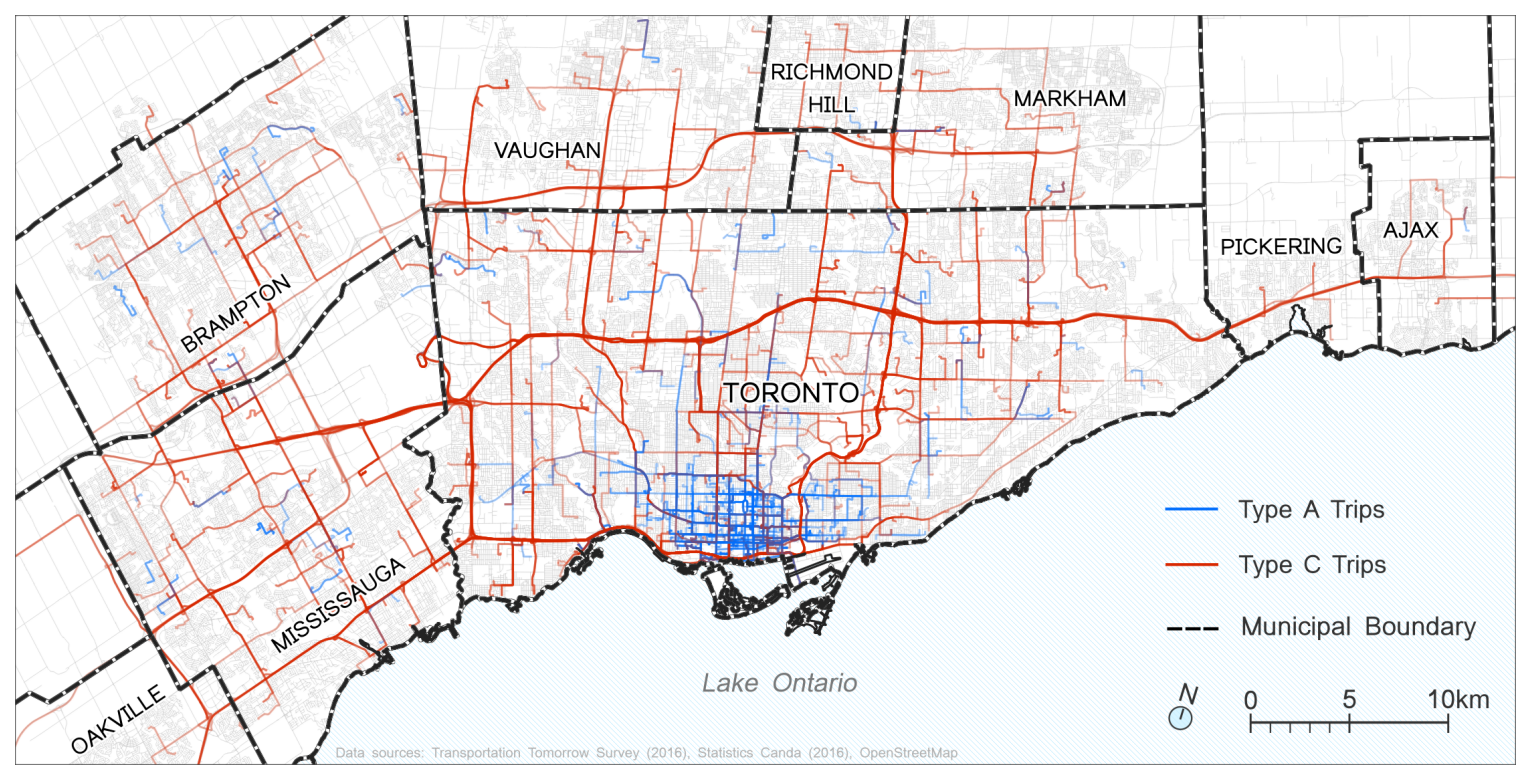

Figure 4. The location of Type A and Type C RH trips

\subsection{Modelling of RH trip categories}

With an understanding of the factors that influence the position of RH trips along the travel-time difference distribution, we now conduct an ordered logistic regression to assess whether these factors are strong enough to affect the probability of a trip belonging to a specific category as defined above. Ordered logit and ordered probit regressions have been used to appropriately model travel-time categories before in the literature (CastilloManzano and Lopez-Valpuesta, 2014; Silveira Neto et al., 2015). We decided on a logit specification, as this maximizes the log pseudo-likelihood (-961.12) when compared to a probit specification (-967.34). Initial variable selection is determined using bivariate statistical tests, and a final reduced model is obtained using a backward stepwise selection process. McFadden's pseudo R-square ( $\rho^{2}$ is used to assess model fit. In addition to reporting on the regression coefficients, we provide results as marginal effects on class membership probability. The reduced model is presented in Table 4 alongside the explanatory variables' corresponding marginal effects. 
Table 4. Ordered logistic model of RH trip categories

\begin{tabular}{|c|c|c|c|c|c|}
\hline \multicolumn{6}{|c|}{ Model Summary } \\
\hline \multirow{3}{*}{$\begin{aligned} \mathrm{n} & =1,578 \\
\rho^{2} & =0.440\end{aligned}$} & \multicolumn{3}{|c|}{$\beta$} & & \\
\hline & Type A | Type B & 6.226 & $0.000 * * *$ & & \\
\hline & Type B | Type C & 10.140 & $0.000 * * *$ & & \\
\hline \multirow{2}{*}{ Variables } & & \multicolumn{4}{|c|}{ Marginal Effects on Probabilities } \\
\hline & & $\beta$ & $p$ & Type A & Type C \\
\hline \multirow[t]{2}{*}{ Transit pass } & Yes & Reference & & & \\
\hline & No & 0.241 & 0.134 & -0.025 & 0.027 \\
\hline \multirow[t]{5}{*}{ Start time } & Morning (5 - 10am) & Reference & & & \\
\hline & Midday (10am - 3pm) & 0.931 & $0.000 * * *$ & -0.070 & 0.141 \\
\hline & Afternoon (3-7pm) & -0.165 & 0.390 & 0.017 & -0.019 \\
\hline & Evening $(7-11 \mathrm{pm})$ & 0.223 & 0.289 & -0.021 & 0.028 \\
\hline & Night (11pm - 5am) & 0.002 & 0.993 & -0.000 & 0.000 \\
\hline \multirow[t]{5}{*}{ Purpose } & $\mathrm{HBW}$ & Reference & & & \\
\hline & HBSc & -0.472 & $0.061^{*}$ & 0.054 & -0.049 \\
\hline & HBSh & -0.688 & $0.013 * *$ & 0.085 & -0.066 \\
\hline & $\mathrm{HBO}$ & -0.167 & 0.304 & 0.017 & -0.020 \\
\hline & Non-Home & -0.400 & $0.039 * *$ & 0.044 & -0.043 \\
\hline \multirow[t]{3}{*}{ Geography } & City of Toronto trip & Reference & & & \\
\hline & City to/from suburb trip & 0.922 & $0.001 * * *$ & -0.069 & 0.141 \\
\hline & Suburban trip & -0.270 & 0.231 & 0.029 & -0.030 \\
\hline $\log (\text { wait-time })^{a}$ & & 2.239 & $0.000 * * *$ & -0.220 & 0.267 \\
\hline Walk-time & & 0.243 & $0.000 * * *$ & -0.024 & 0.029 \\
\hline \multirow{3}{*}{$\begin{array}{l}\text { Number of } \\
\text { transfers }\end{array}$} & 0 & Reference & & & \\
\hline & 1 & 1.627 & $0.000 * * *$ & -0.146 & 0.224 \\
\hline & $2+$ & 3.193 & $0.000 * * *$ & -0.161 & 0.616 \\
\hline Transit Cost & & -0.131 & $0.006^{* * *}$ & 0.013 & -0.016 \\
\hline Subway & & -1.003 & $0.000 * * *$ & 0.115 & -0.106 \\
\hline Streetcar & & 0.828 & $0.000 * * *$ & -0.075 & 0.108 \\
\hline
\end{tabular}

Note: ${ }^{*} \mathrm{p}<0.1 ; * * \mathrm{p}<0.05 ; * * * \mathrm{p}<0.01$

${ }^{\mathrm{a}}$ The wait-time variable is $\log$ transformed because some of the extreme observations have predicted probabilities indistinguishable from 1.

Overall, RH trips that begin midday $(10 \mathrm{am}-3 \mathrm{pm})$ are more likely to belong to Type C trips in reference to morning peak period trips, even once controlling for socioeconomic factors and other trip characteristics. RH trips for Home-based shopping purposes are more likely to be of Type A in comparison to the reference, Home-based work purpose trips.

As expected, RH trips that either begin or end in the City of Toronto and span beyond its municipal boundaries (and the service area of the TTC) are more likely to 
belong to the Type $\mathrm{C}$ category than those entirely comprised within the City limits. A longer walk-time, wait time, and a greater number of transfers are also all associated with a higher probability of belonging to the Type $\mathrm{C}$ group. Alternative transit trips requiring the use of a subway are more likely to belong to Type A, whereas those necessitating a streetcar have a higher chance of belonging to Type C. This could be due to subways having their own dedicated lanes, and to streetcars often having to share congested roadways with cars. Interestingly bus trips do not appear to be significant in our model, which may likely be due to their prominence as a transit alternative.

From the above analysis it becomes apparent that factors deemed significant in our previous OLS regression are also generally found to impact the probability of belonging to specific RH trip categories. The purpose of conducting this second regression model is first to substantiate the significance of our coefficients, but second and foremost to authenticate the use of these categories for future policy work. We may now discuss the effects of specific user or trip characteristics on the probability of belonging to particular RH trip categories, while keeping all else constant. Understanding the factors that influence the likelihood of partaking in Type A trips will enable policymakers to effectively design regulations to limit their occurrence.

\section{Discussion and Recommendations}

The objective of this paper is to determine the degree to which RH trips compete or supplement public transit, and to uncover the user and trip characteristics that influence the travel-time difference between these modes. Overall, 30.6\% of RH trips in our sample are classified as Type A, those with $\Delta<15$ minutes. These are particularly damaging for transit agencies as they compete directly with trips that fall within 
reasonable transit service expectations and potentially deprive agencies of fare revenues. Type C trips, with $\Delta>30$ minutes, account for $26.9 \%$ of our sample and are often entirely, or at least partially, located in the outer regions of the City, and in areas with lower transit frequency. These correspond to trips that Rayle et al. (2016) define as filling gaps within the public transit network, and may in some cases, actually benefit transit agencies by ensuring that some of their passengers can purchase mobility in instances of low transit supply. We also removed $69 \mathrm{RH}$ trips from our dataset as they did not have viable transit alternatives and could therefore not be included in the travel-time difference analysis, but recognize that these are also likely filling gaps in particularly poor transit service and including them in our analysis would have increased the proportion of supplementary trips. This of course, is assuming that transit passengers can afford to use RH services, as these have been characterized as prohibitive in the past (Young and Farber, 2019b).

An important finding from our analysis is that trip characteristics have a much more significant impact on $\Delta$ than person-level attributes. It appears that once an individual has decided to use $\mathrm{RH}$, their personal characteristics will not influence the type of trip they partake in. Instead, it is the location, timing, purpose of RH trips, as well as the characteristics of the fastest transit alternative that predict how much travel-time they save by using RH rather than transit. The type of transit mode being used in lieu of RH also influences the position of trips along the travel-time difference distribution. This corroborates Clewlow and Mishra's (2017) finding that RH services do not impact transit modes equally, and reiterates the importance to consider them separately.

Given the high percentage of RH trips that directly compete with transit, we recommend that governments should introduce an additional tax to reduce the occurrence 
of RH trips that can easily be replaced by transit (Type A). More specifically, our recommendation is to impose an additional tax upon Type A trips, as these we argue, should be discouraged since they have viable transit alternatives and compete directly with trips that fall within reasonable transit service expectations. Our intention is not to eliminate or prevent such trips from happening, but rather to impose a slight additional burden upon users to nudge them back towards transit when possible and to account for a portion of the transit agency's lost revenue when impossible or unreasonable.

In order to implement this tax, we recommend that cities work with mobility platforms. RH companies such as Didi Chuxing are increasingly starting to offer a holistic choice set of travel alternatives, including public transit, within their smartphone platforms to enable a more effective mobility experience for users, and ultimately gain headway in the Mobility-as-a-Service (MaaS) market. It would be relatively straightforward to operationalize a Type A trip tax within an integrated MaaS platform. While beyond the scope of this study, forcing RH companies to offer a holistic choice set of alternatives would also enable governments to tax short trips that could have been done by active modes of travel.

We also recommend that cities carefully consider subsidizing RH trips that fill a gap in poor transit service, but acknowledge that this may interfere with existing sustainable transport objectives. Discouraging single-occupant vehicle (SOV) trips should be a priority, but not at the expense of suppressed participation rates among the transport poor (Lucas et al., 2016). For the transport poor, RH may be one of the only viable travel options to reach important activity destinations. From a sustainability perspective, subsidizing RH trips in areas with low transit demand may make more sense 
than running buses with low occupancy, and while subsidizing RH trips may contribute to more driving, it may also, as suggested by Rayle et al. (2016), facilitate not owning a private vehicle by providing a suitable alternative to transit when it does not provide a high level of service.

To balance the competing goals of environmental sustainability while promoting increased activity participation, governments could subsidize the first/last mile of trips that significantly prolong transit travel-times. In our dataset, there are $212(13.4 \%)$ equivalent transit trips that contain such problematic first/last mile segments (measured as having an initial walk- and/or wait-time or end walk-time $>15$ minutes). By subsidizing RH trips in lieu of these inefficient trip segments, governments could therefore encourage $\mathrm{RH}$ to behave as a complement to transit, and provide more equitable travel opportunity to individuals living in areas with poor transit service. We must tread lightly here, however, since it is not clear that subsidizing Type $\mathrm{C}$ RH trips is a more effective transport policy than simply investing more in transit or reducing transit fares. To be certain, all of this requires more research and analysis and assumes that $\mathrm{RH}$ companies will be financially viable in the long term, given that they are currently only able to operate via venture capital investments. Finally, while our dataset does not provide any information about vehicle occupancy rate, we are confident that there were very few pooled trips in our sample. A recent report found that 26\% of Uber trips in 2018 were made by UberPool and that only $18 \%$ of these were actually successfully matched. In our sample, the proportion of UberPool trips was likely lower, and the proportion unmatched higher, since UberPool was only a few months old in September 2016, when the TTS was collected (City of Toronto, 2019). We encourage governments to collect 
occupancy data from RH companies directly, and further endorse limiting the above subsidy to pooled trips, as this would render RH more affordable while promoting sustainable behaviours.

\section{Conclusion}

Our analysis provides a better understanding of the competition between RH trips and transit alternatives, and the factors that make certain riders choose RH despite transit being a reasonably viable alternative. By examining RH trips individually, we discover that $\mathrm{RH}$ services act both as a substitute and supplement to transit. For this reason, we refrain from collectively defining the impact of $\mathrm{RH}$ services on transit, and attempt instead to segment RH trips by their travel-time difference with transit. Overall we find that $30.6 \%$ of $\mathrm{RH}$ trips in our sample have transit alternatives of similar duration and compete directly with these services (Type A). We also find that $26.9 \%$ of RH trips have poor transit-based alternatives (Type C), and are therefore less directly competitive in nature. In light of these findings, we recommend imposing an additional tax upon Type A $\mathrm{RH}$ trips to discourage their occurrence and recapture a portion of lost transit revenues. We also consider subsidizing $\mathrm{RH}$ trips that fill a gap in poor transit service, and particularly inefficient first/last mile segments that significantly prolong the duration of transit alternatives. Fortunately, whether RH companies are gradually warming up to the idea of sharing data, or simply that policymakers are beginning to mandate they provide this information in exchange for the right to operate legally in their jurisdiction, $\mathrm{RH}$ are now granting governments and researchers with access to their datasets. Combined with exhaustive travel surveys such as the 2016 TTS, the use of these datasets could reveal the proportion and composition of pooled RH trips as well as the occurrence and impact of 
surge pricing, which in turn could further inform and enhance the policies proposed in this study.

\section{Acknowledgements}

The authors would like to thank the Fonds de Recherche du Québec - Société et Culture (FRQSC) for funding this research project. 
Appendix A. Ordinary least square regression to determine the factors that influence the absolute difference in travel-time between RH trips and their fastest transit alternative.

\begin{tabular}{|c|c|c|c|}
\hline \multirow{2}{*}{ Variables } & & \multicolumn{2}{|c|}{ Dependent variable: $\log (\Delta)$} \\
\hline & & Full model & Reduced model \\
\hline \multirow{5}{*}{ Income } & $\$ 0-39,999$ & 0.019 & - \\
\hline & $\$ 40,000-59,999$ & 0.005 & - \\
\hline & $\$ 60,000-99,999$ & -0.014 & - \\
\hline & $\$ 100,000+$ & Reference & - \\
\hline & Decline/don't know & $0.062 * *$ & - \\
\hline \multirow[t]{3}{*}{ Age } & $18-29$ & Reference & - \\
\hline & $30-59$ & 0.030 & - \\
\hline & $60+$ & -0.016 & - \\
\hline \multirow{2}{*}{ Gender } & Female & Reference & - \\
\hline & Male & $0.037 * *$ & - \\
\hline \multirow[t]{2}{*}{ Driver's licence } & Yes & Reference & - \\
\hline & No & -0.002 & - \\
\hline \multirow[t]{2}{*}{ Transit pass } & Yes & Reference & - \\
\hline & No & 0.012 & - \\
\hline \multirow[t]{4}{*}{ Number of vehicles } & 0 & Reference & Reference \\
\hline & 1 & -0.016 & -0.013 \\
\hline & 2 & $0.056 * *$ & $0.055 * *$ \\
\hline & $3+$ & 0.017 & 0.019 \\
\hline \multirow[t]{5}{*}{ Start-time } & Morning (5 - 10am) & Reference & Reference \\
\hline & Midday (10am - 3pm) & $0.132 * * *$ & $0.137 * * *$ \\
\hline & Afternoon $(3-7 \mathrm{pm})$ & 0.006 & 0.006 \\
\hline & Evening $(7-11 \mathrm{pm})$ & $0.053 *$ & $0.051 *$ \\
\hline & Night (11pm - 5am) & 0.005 & 0.004 \\
\hline \multirow{5}{*}{ Purpose } & $\mathrm{HBW}$ & Reference & Reference \\
\hline & HBSc & -0.012 & -0.026 \\
\hline & HBSh & $-0.133 * * *$ & $-0.130 * * *$ \\
\hline & HBO & $-0.051 * *$ & $-0.049 * *$ \\
\hline & Non-Home & $-0.096 * * *$ & $-0.096 * * *$ \\
\hline \multirow[t]{3}{*}{ Geography } & City of Toronto trip & Reference & Reference \\
\hline & City to/from suburb trip & $0.107 * * *$ & $0.099 * * *$ \\
\hline & Suburban trip & -0.027 & -0.029 \\
\hline $\log$ (transit wait-time $)$ & & $0.483 * * *$ & $0.485 * * *$ \\
\hline $\log ($ walk-time $)$ & & $0.532 * * *$ & $0.529 * * *$ \\
\hline \multirow[t]{3}{*}{ Number of transfers } & 0 & Reference & Reference \\
\hline & 1 & $0.227 * * *$ & $0.227 * * *$ \\
\hline & $2+$ & $0.433 * * *$ & $0.431 * * *$ \\
\hline $\log ($ transit cost $)$ & & -0.009 & - \\
\hline Subway & & $-0.077 * * *$ & $-0.079 * * *$ \\
\hline Streetcar & & $0.184 * * *$ & $0.180 * * *$ \\
\hline Bus & & $0.094 * * *$ & $0.095 * * *$ \\
\hline Constant & & $-0.479 * * *$ & $-0.505^{* * *}$ \\
\hline Number of observations: & & $1,514^{\mathrm{a}}$ & $1,514^{\mathrm{a}}$ \\
\hline R-square & & 0.748 & 0.747 \\
\hline Adjusted R-square & & 0.743 & 0.743 \\
\hline
\end{tabular}

Note: ${ }^{*} \mathrm{p}<0.1 ; * * \mathrm{p}<0.05 ; * * * \mathrm{p}<0.01$

a Sample of 1,514 rather than 1,578 observations because of the removal of outliers. 
Appendix B. Maps depicting the origin and destination of Type A and Type C RH trips.

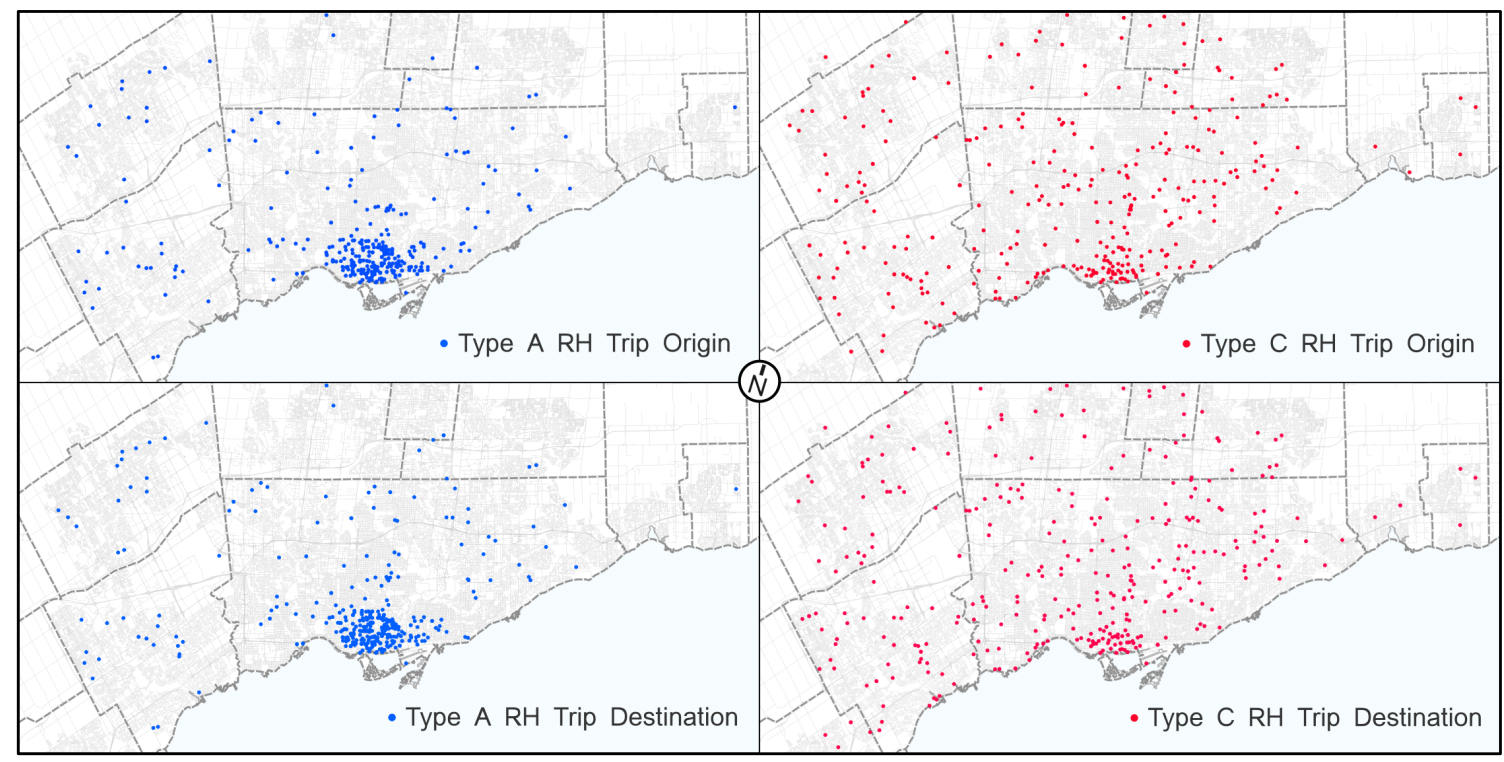




\section{References}

Allen, J., \& Farber, S. (2018). How time-use and transportation barriers limit on-campus participation of university students. Travel behaviour and society, 13, 174-182.

Allen, J., \& Farber, S. (2019). Sizing up transport poverty: A national scale accounting of low-income households suffering from inaccessibility in Canada, and what to do about it. Transport policy, 74, 214-223.

Bhat, C. R., \& Sardesai, R. (2006). The impact of stop-making and travel-time reliability on commute mode choice. Transportation Research Part B: Methodological, 40(9), 709-730.

Bialik, C., Flowers, A., Fisher-Baum, R., \& Mehta, D. (2015). Uber Is Serving New York's Outer Boroughs More Than Taxis Are, FiveThirtyEight. https://fivethirtyeight.com/features/uber-is-serving-new-yorks-outer-boroughsmore-than-taxis-are/ (accessed on May 14, 2018).

Castiglione, J., Cooper, D., Sana, B., Tischler, D., Chang, T., Erhardt, G., Roy, S., Chen, M., and Mucci. A. (2018). TNCs \& Congestion. San Francisco County Transportation Authority. $35 \mathrm{p}$.

Castillo-Manzano, J. I., \& Lopez-Valpuesta, L. (2014). Can LCCs' economic efficiency create negative externalities for air transport? An analysis of passenger waiting time. Applied Economics Letters, 21(13), 878-881.

City of Toronto. (2019). The Transportation Impacts of Vehicle-for-hire in the City of Toronto. Big Data Innovation Team, Transport Services City of Toronto in Partnership with the University of Toronto Transportation Research Institute. 64 p.

Clewlow, R., Mishra, G. (2017). Disruptive Transportation: The Adoption, Utilization, and Impacts of Ridesourcing in the United States. Institute of Transportation Studies, University of California, Davis, Davis, CA. Report UCD-ITS-RR-17-07. $38 \mathrm{p}$.

Data Management Group, (2017). TTS Introduction. $\mathrm{http} / / / \mathrm{dmg}$.utoronto.ca/transportation-tomorrow-survey/tts-introduction (accessed on April 24, 2018).

Erhardt, G. D., Roy, S., Cooper, D., Sana, B., Chen, M., \& Castiglione, J. (2019). Do transportation network companies decrease or increase congestion?. Science advances, 5(5), eaau2670.

Farber, S., Ritter, B., \& Fu, L. (2016). Space-time mismatch between transit service and observed travel patterns in the Wasatch Front, Utah: A social equity perspective. Travel Behaviour and Society, 4, 40-48. 
Feigon, S., \& Murphy, C. (2016). Shared mobility and the transformation of public transit (No. Project J-11, Task 21).

Fitzsimmons, E. G. (2017). Subway Ridership Declines in New York. Is Uber to Blame? The New York Times. https://www.nytimes.com/2017/02/23/nyregion/new-yorkcity-subway-ridership.html

Frank, L., Bradley, M., Kavage, S., Chapman, J., \& Lawton, T. K. (2008). Urban form, travel time, and cost relationships with tour complexity and mode choice. Transportation, 35(1): 37-54.

Gehrke, S. R., Felix, A., \& Reardon, T. G. (2019). Substitution of ride-hailing services for more sustainable travel options in the greater Boston region. Transportation Research Record, 2673(1), 438-446.

Hall, J. D., Palsson, C., \& Price, J. (2017). Is Uber a substitute or complement for public transit? Journal of Urban Economics, 108, 36-50.

Henao, A. (2017). Impacts of Ridesourcing - Lyft and Uber - on Transportation Including VMT, Mode Replacement, Parking, and Travel Behavior. Ph.D. Thesis, University of Colorado at Denver. ISBN 9781369757804.

Henao, A., \& Marshall, W. E. (2018). The impact of ride-hailing on vehicle miles traveled. Transportation, 1-22.

Howell, N. A., Farber, S., Widener, M. J., Allen, J., \& Booth, G. L. (2018). Association between residential self-selection and non-residential built environment exposures. Health \& place, 54, 149-154.

Hulchanski, J. D. (2010). The three cities within Toronto. Toronto: Cities Centre.

Iqbal, M. (2018). Uber Revenue and Usage Statistics (2018). BusinessofApps. http://www.businessofapps.com/data/uber-statistics/\#1

Komanduri, A., Wafa, Z., Proussaloglou, K., \& Jacobs, S. (2018). Assessing the impact of app-based ride share systems in an urban context: Findings from Austin. Transportation Research Record, 2672(7), 34-46.

Lucas, K., Mattioli, G., Verlinghieri, E., \& Guzman, A. (2016). Transport poverty and its adverse social consequences. In Proceedings of the institution of civil engineerstransport (Vol. 169, No. 6, pp. 353-365). Thomas Telford (ICE Publishing).

PSTA. (2018). TD Late Shift and Urgent TD Program Quarterly Report. Pinellas Suncoast Transit Authority. 5 p. 
Rayle, L., Dai, D., Chan, N., Cervero, R., \& Shaheen, S. (2016). Just a better taxi? A survey-based comparison of taxis, transit, and ridesourcing services in San Francisco. Transport Policy 45, 168-178.

Schaller, B. (2017). Unsustainable? The Growth of App-Based Ride Services and Traffic, Travel and the Future of New York City. Schaller Consulting.

Schaller Consulting. (2018). The New Automobility: Lyft, Uber and the Future of American Cities. http://www.schallerconsult.com/rideservices/automobility.pdf (accessed on March 4, 2018).

Silveira Neto, R., Duarte, G., \& Páez, A. (2015). Gender and commuting time in São Paulo metropolitan region. Urban Studies, 52(2), 298-313.

Statistics Canada, 2016. Census Profile, 2016 Census, Toronto. http://www12.statcan.gc.ca/census-recensement/2016/dp-pd/index-eng.cfm (accessed on May 14, 2018).

Silver, N., \& Fischer-Baum, R. (2015). Public Transit Should Be Uber's New Best Friend. FiveThirtyEight. https://fivethirtyeight.com/features/public-transit-shouldbe-ubers-new-best-friend/ (accessed on June 2, 2018).

Tirachini, A., \& del Río, M. (2019). Ride-hailing in Santiago de Chile: Users' characterisation and effects on travel behaviour. Transport Policy, 82, 46-57.

Toronto. (2018). Public Consultation Summary: Review of Chapter 546, Licensing of Vehicles-for-hire. Toronto Municipal Licensing \& Standards. 11 p.

Transportation Tomorrow Survey. (2016). TTS 2016 Data Guide http://dmg.utoronto.ca/pdf/tts/2016/2016TTS_DataGuide.pdf (accessed on April 24, 2018).

Uber. (2019a). About Us. https://www.uber.com/en-CA/about/

Uber. (2019b). Uber price estimator. https://www.uber.com/ca/en/price-estimate/

Wenting, L., Shalaby, A., and Habib, N. K. (Forthcoming). The relationship between PTC and public transit: descriptive analysis. UTTRI Technical Support for the City of Toronto Vehicle for Hire Bylaw Review, Report No. 5. 60 p.

Wessel, N., \& Farber, S. (2019). On the Accuracy of Schedule-Based GTFS for Measuring Accessibility (No. 19-04587).

Young, M. (2019). Ride-hailing's Impact on Canadian Cities: Now Let's Consider the Long Game. Canadian Geographer, 63: 171-175. 
Young, M., \& S. Farber. (2019a). The who, why, when of Uber and other ride-hailing trips: An examination of a large sample household travel survey. Transportation Research Part A 119: 383-392.

Young, M., \& S. Farber. (2019b). Ride-hailing platforms are shaping the future of mobility, but for whom? The Platform Economy and the City: Urban Peril and Promise in the New Digital Economy edited by Austin Zwick and Zachary Spicer. McGill-Queens University Press. https://doi.org/10.31219/osf.io/pz7fk

Zwick, A., \& Spicer, Z. (2018). Good or bad? Ridesharing's impact on Canadian cities. The Canadian Geographer/Le Géographe canadien, 62(4), 430-436. 